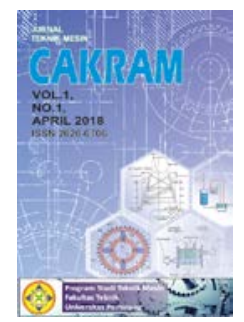

\title{
ANALISA KERUSAKAN SUDU TURBIN UAP MATERIAL MARTENSITIC STAINLESS STEEL 410 PADA STAGE TERAKHIR
}

\author{
Muhamad Cahyadi $^{1}$ \\ ${ }^{1}$ Program Studi Teknik Mesin, Universitas Pamulang, Jl. Surya Kencana No.1, Tangerang Selatan, Indonesia \\ E-mail : mcahyadie89@gmail.com
}

Masuk : 14 Agustus 2019

Direvisi : 5 September 2019

Disetujui : 22 September 2019

\begin{abstract}
Abstrak: Sudu dari turbin uap merupakan komponen penting dalam pembangkit listrik, dalam mengubah gerakan linier dari uap bersuhu dan tekanan tinggi mengalir menuruni gradient tekanan menjadi gerakan berputar dari poros turbin. Jika sudu turbin mengalami kerusakan/kegagalan, pembangkit listrik akan berhenti beroperasi. Penelitian ini bertujuan untuk menganalisa dan menentukan jenis-jenis kerusakan serta penyebab utama kerusakan sudu turbin, agar mendapatkan petunjuk yang berguna untuk mencegah timbul dan meluasnya tingkat kerusakan serta langkah-langkah penanggulangan atau pencegahan sesuai dengan penyebab kerusakan, meminimalisir terjadinya breakdown dengan tujuan meningkatkan reliability machine, sehingga pasokan produksi listrik yang ditargetkan dapat terpenuhi dan menentukan jenis sistem pemeliharaan mesin yang efektif dan optimal. Hasil analisa penyebab utama kerusakan terjadi karena putaran tinggi ( over speed ) pada turbin uap yang mengakibatkan overload, penyebab utama kerusakan digunakan untuk pengembangan kualitas sudu turbin serta optimasi berupa perbaikan desain, pemilihan material, perbaikanmanufaktur, cara pemasangan serta penerapan sistem manajemen pemeliharaan yang tepat.
\end{abstract}

Kata kunci: Turbin uap,reliability machine, optimasi

Abstract: Blades from steam turbines are an important component in electricity generation, in changing the linear motion of high temperature and high pressure steam flowing down the pressure gradient into the rotating motion of the turbine shaft. If the turbine blade has damage / failure, the power plant will stop operating. This study aims to analyze and determine the types of damage and the main causes of turbine blade damage, in order to obtain useful instructions to prevent the occurrence and extent of damage and preventive or preventive measures according to the cause of the damage, minimize the occurrence of breakdown with the aim of increasing machine reliability, so that the targeted electricity production supply can be met and determine the type of engine maintenance system that is effective and optimal. The results of the analysis of the main causes of damage occur due to high speed (over speed) in the steam turbine which results in overload, the main cause of damage is used for the development of the quality of the turbine blade and optimization in the form of design improvements, material selection, manufacturing improvements, how to install and implement an appropriate maintenance management system .

Keywords: Steam turbine, machine reliability, optimization 


\section{PENDAHULUAN}

Turbin merupakan mesin penggerak utama yang menggerakan generator dalam sistem Pembangkit Listrik Tenaga Uap (PLTU).Pemeliharaan dan kehandalan (maintenance and reliability) merupakan aktivitas yang berkaitan untuk mempertahankan peralatan sistem kerja mesin dalam kondisi baik untuk waktu tertentu sehingga tidak mengganggu proses produksi. Sudu dari turbin uap merupakan komponen penting dalam pembangkit listrik dalam mengubah gerakan linier dari uap bersuhu dan tekanan tinggi mengalir menuruni gradient tekanan menjadi gerakan berputar dari poros turbin. Jika sudu turbin mengalami kerusakan/kegagalan, pembangkit listrik akan berhenti beroperasi. Hal ini dapat menyebabkan kegagalan dalam waktu yang lama dan kerugian ekonomi dari hasil produksi yang hilang serta perbaikan bagian yang mengalami kerusakan.Secara umum, kerusakan sudu turbin pada baris terakhir dapat terkait oleh banyak kemungkinan kejadian seperti stress corrosion, corrosion fatigue, water erosion dan fatigue.

Kerusakan pada sudu turbin uap stage terakhir ditemukan adanya efek patah static akibat putaran tinggi turbin uap yang tidak terkendali (over speed). Turbin uap mengalami kerusakan/kegagalan ketika start-up. Turbin uap memiliki 2 putaran, pertama pada putaran 5000-6000 rpm dan kedua pada putaran 11000-12000 rpm dan biasanya turbin uap biasa dioperasikan diantara putaran pertama dan kedua, yaitu sekitar 8500 rpm. Ketika turbin uap start-up telah melewati putaran pertama, turbin tidak terkendali dan putarannya terus naik (over speed) sampai mencapai putaran kedua, dan turbin uap kemudian berhenti.Melihat hal ini harus dilakukan pemasangan electrical switch untuk mencegah putaran tinggi yang tidak terkendali/ terkontrol dengan baik pada turbin uap saat di operasikan.

Beberapa perbaikan yang dapat digunakan untuk meminimalisir terjadinya kerusakan yang ada di dalam turbin uap dengan melakukan SOP pemasangan sudu turbin dan pastikan dudukan/seatnya kencang. Pada penelitian ini menggunakan alat mechanical vibration test yang dapat mengidentifikasi keketatan dudukan sudu pada groove nya.

\section{METODOLOGI}

Pada tahap ini akan dilakukan pengumpulan data primer dan sekunder melalui inspeksi lapangan, pengambilan sampel uji, data desain engineering dan analisa pemeriksaan sudu turbin secara visual sampai dengan mendapatkan penyebab terjadinya kerusakan dan penentuan kelayakan operasi turbin blade (sudu turbin).

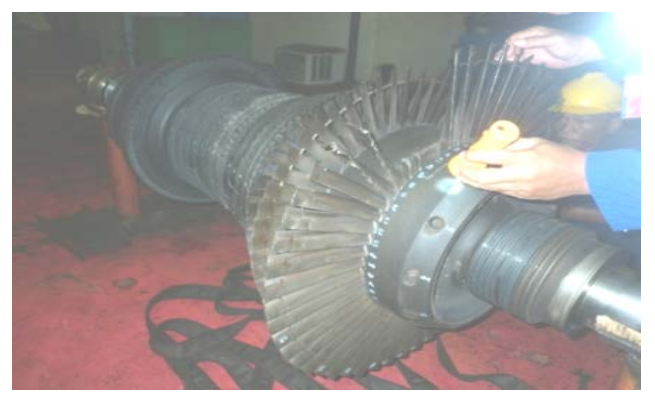

Gambar 1.a). Pada gambar di atas merupakan turbin uap yang mengalami kerusakan pada sudu turbin stage terakhir, sedangkan sudu pada stage 1-5 tidak terjadi kerusakan. ini menunjukkan tidak adanya indikasi kerusakan oleh foreign object. Jumlah sudu turbin pada stage terakhir adalah 55, sudu 46 dan 47 telah lepas dari dudukan sedangkan sudu 21, 22, 23, 24, 25, 48, 49 mengalami patah statik. 
Muhamad Cahyadi, Analisa Kerusakan Sudu Turbin Uap Material Martensitic Stainless Steel 410 Pada Stage Terakhir
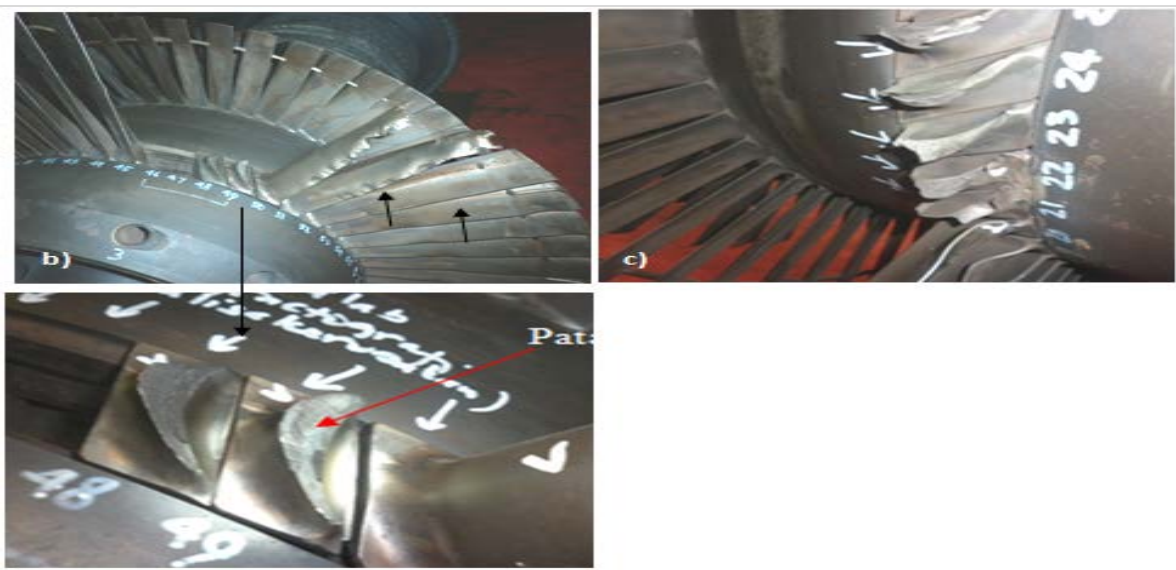

Gambar 1.b-c).Berupa patah overload/statik yang mempunyai bentuk sudut $45^{\circ}$ dan tidak ditemukan adanya indikasi patah lelah.

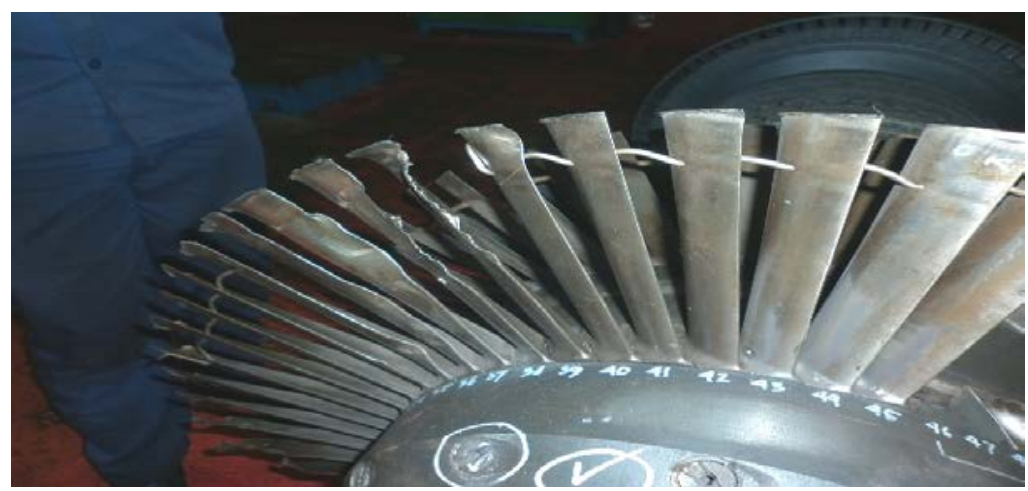

Gambar 1.d).Deformasi pada ujung sudu dan kerusakan lain sebagai efek benturan dari sudu yang terlepas/patah.

\begin{tabular}{|l|c|}
\hline \multirow{2}{*}{ Unsure } & R e s u l t ( wt \% ) \\
\cline { 2 - 2 } & $\begin{array}{c}\text { Specification sheet: } \\
\text { Alloy 410 (UNS } \\
\text { S41000) }\end{array}$ \\
\hline Carbon (C) & $0.08-0.15$ \\
\hline Silicon (Si) & 1.0 \\
\hline Manganese (Mn) & 1.0 \\
\hline Chromium (Cr) & $11.5-13.5$ \\
\hline Nickel (Ni) & 0.75 \\
\hline Phosphorus (P) & 0.04 \\
\hline Iron (Fe) & $74.56-85.63$ \\
\hline
\end{tabular}




\section{HASIL DAN PEMBAHASAN}

Table1 . Data perbandingan pengujian kimiasudu turbinuap dan Alloy 410 (UNS

\begin{tabular}{|l|l|}
\hline \multirow{2}{*}{ Unsure } & Result (wt \%) \\
\cline { 2 - 3 } & Sudu turbin uap \\
\hline $\mathrm{Fe}$ & 85.2 \\
\hline $\mathrm{C}$ & 0.392 \\
\hline $\mathrm{Si}$ & 0.456 \\
\hline $\mathrm{Mn}$ & 0.486 \\
\hline $\mathrm{Cr}$ & 12.7 \\
\hline $\mathrm{N}$ & 0.166 \\
\hline $\mathrm{Mo}$ & 0.0796 \\
\hline $\mathrm{Cu}$ & 0.119 \\
\hline $\mathrm{Al}$ & 0.0027 \\
\hline $\mathrm{V}$ & 0.0583 \\
\hline $\mathrm{Ti}$ & 0.0018 \\
\hline $\mathrm{S}$ & 0.0030 \\
\hline $\mathrm{P}$ & 0.0191 \\
\hline $\mathrm{Co}$ & 0.0361 \\
\hline $\mathrm{Nb}$ & 0.255 \\
\hline $\mathrm{W}$ & 0.0400 \\
\hline $\mathrm{Pb}$ & 0.0150 \\
\hline & \\
\hline
\end{tabular}

komposisi

S41000)

\begin{tabular}{|l|c|}
\hline \multirow{2}{*}{ Unsure } & R e s u l t (wt \%) \\
\cline { 2 - 2 } & $\begin{array}{c}\text { Specification sheet: } \\
\text { Alloy 410 (UNS } \\
\text { S41000) }\end{array}$ \\
\hline Carbon (C) & $0.08-0.15$ \\
\hline Silicon (Si) & 1.0 \\
\hline Manganese (Mn) & 1.0 \\
\hline Chromium (Cr) & $11.5-13.5$ \\
\hline Nickel (Ni) & 0.75 \\
\hline Phosphorus (P) & 0.04 \\
\hline Iron (Fe) & $74.56-85.63$ \\
\hline
\end{tabular}

Dari analisa komposisi kimiaTurbin Blade(tabel 1) yang mengalami kerusakan dapat disimpulkan bahwa:

1) Unsur karbon (C) pada Turbin Blade(0.392\% C) memiliki kandungan karbon yang tinggi tidak sesuai dengan standar UNSS41000 (0.08 - 0.15\%C), memperlihatkan perbedaan komposisi karbon yangsignificant sehingga Turbin Blade terpengaruh efek panas dengan berkurangnya sifat kekerasan, sifat tarik, elongasi, kekuatan impact namun mempercepat titik lebur.

2) Unsur silikon (Si) pada Turbin Blade(0.456\% Si) sesuai dengan standar UNS S41000 (1.0\%Si), lebih rendah dibandingkan standartsehingga ketahanan material handal dan sifat mekanis logam yang baik.

3) Unsur mangan (Mn) pada Turbin Blade (0.486\%Mn) sesuai dengan standar UNS S41000 (1.0\% Mn), lebih rendah sehingga material tidak tahan pada temperatur tinggi.

4) Unsur phosfor (P) padaTurbin Blade (0.0191\%P) sesuai dengan standar UNS S41000 (0.04\%P max), lebih rendah sehingga mempengaruhi terbentuknya fasa ferit dan meningkatkan ketahanan korosi dan oksidasi.

5) Unsur Chromium (Cr) padaTurbin Blade(12.7\% Cr) sesuai dengan standar UNS (11.5 - 13.5\% Cr), sehingga akan terpengaruh komposisinya jika unsur - unsur lainnya (Ni, Cu Al, Mo, V, Cu,W, Ti, Sn, $\mathrm{Al}, \mathrm{Pb}, \mathrm{Nb}$ ) berubah. 


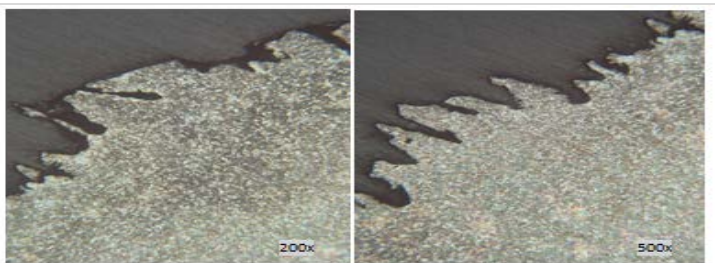

6)

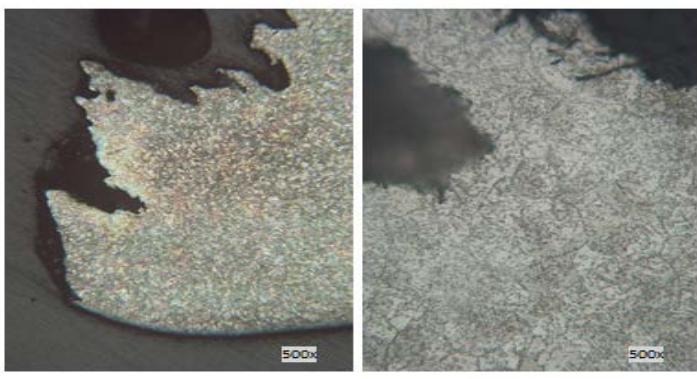

7) Gambar 2.Photo makro Sampel 3 uji metalografi pada sudu No. 50

8) Sampel sudu turbin no. 50 (gambar 2) berupa hasil patahan yang dipotong melintang daerah ujung leading edge, struktur mikro berupa martensite tempered dan bainite dalam kondisi normal dan setelah dietsa dengan kalling reagent terlihat bentuk yang disebabkan oleh tetesan air (impingement water droplets) akibat kondensasi, struktur mikro berupa matrik austenite dengan jaringan karbida menyebar merata.
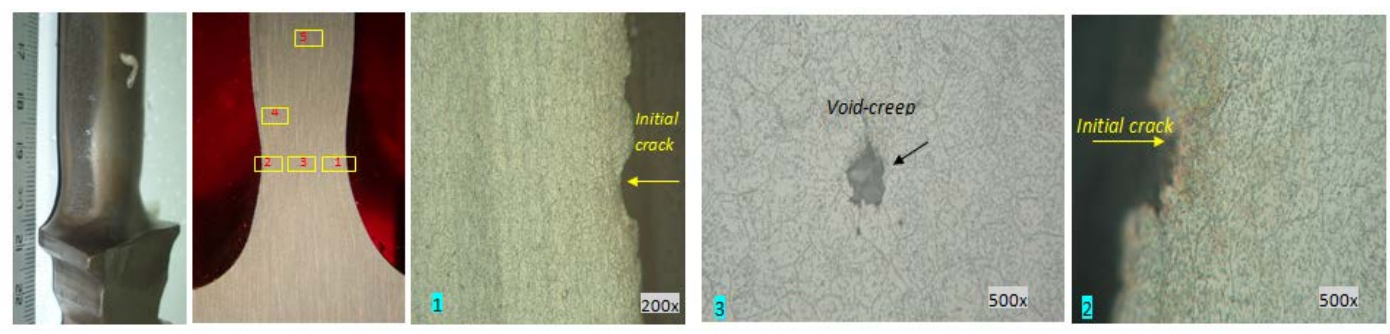

Gambar 3.Potongan material yang mengalami necking dan initial crack, serta Pengecilan struktur dan void-cacat peregangan.

Dalam pengujian metalografi pada sudu 50 yang dipotong memanjang (gambar 3) pada daerah yang mengalami necking di lokasi 1, 2 daerah tepi, struktur mikro berupa matrik bainit-austenite dengan jaringan karbida menyebar merata dan sudah terjadi rekahan initial crack. Pada lokasi 3 dan 4 mengalami pengecilan struktur dan sudah terjadi void-cacat peregangan sedangkan lokasi 5 kondisi strukturnya masih berbentuk normal. 
Tabel 2 Hasil uji kekerasan sudu turbin.

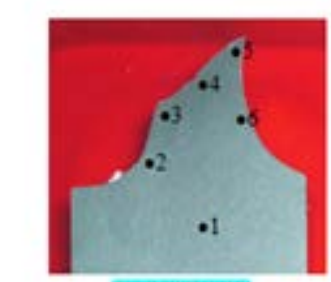

SuduNo. 23

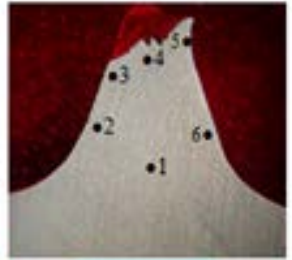

Sudu No. 24

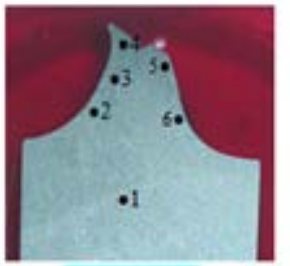

Sudu No. 48

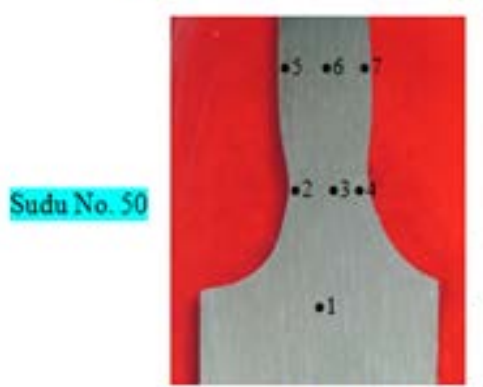

Sampel 1

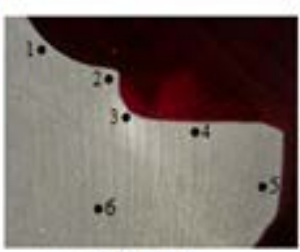

Sampel 2

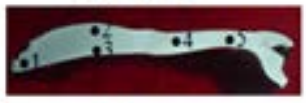

Sampel 3

Tabel 1. Hasil Uji Kekerasan Sudu Turbin

\begin{tabular}{|c|c|c|c|c|c|c|}
\hline \multirow{3}{*}{ Lokasi Uji } & \multicolumn{6}{|c|}{ Nilai Kekerasan Vickers (HV) $\mathrm{P}=\mathbf{5} \mathrm{kgf}$} \\
\hline & \multirow{2}{*}{$\begin{array}{c}\text { Sudu } \\
\text { Turbin } \\
\text { No. } 23\end{array}$} & \multirow{2}{*}{$\begin{array}{c}\text { Sudu } \\
\text { Turbin } \\
\text { No. } 24 \\
\end{array}$} & \multirow{2}{*}{$\begin{array}{c}\text { Sudu } \\
\text { Turbin } \\
\text { No. } 48 \\
\end{array}$} & \multicolumn{3}{|c|}{ Sudu Turbin No. 50} \\
\hline & & & & Sampel 1 & Sampel 2 & Sampel 3 \\
\hline 1 & 227 & 303 & 249 & 208 & 225 & 232 \\
\hline 2 & 241 & 306 & 249 & 246 & 230 & 285 \\
\hline 3 & 274 & 303 & 246 & 286 & 232 & 244 \\
\hline 4 & 274 & 277 & 260 & 299 & 271 & 244 \\
\hline 5 & 277 & 288 & 306 & 232 & 274 & 244 \\
\hline 6 & 277 & 274 & 309 & 227 & 236 & - \\
\hline 7 & - & - & - & 218 & - & - \\
\hline
\end{tabular}

Nilai standar untuk stainless steel type 410 adalah $\max .230 \mathrm{HV}$ (dianil).

Dari tabel 2 diperoleh nilai kekerasan pada permukaan Turbin Blade (sudu turbin) yang telah diperiksa (No. 23, 24, 48, 49 dan 50) berkisar antara 204-309 HV dengan nilai kekerasan diatas standar, namun standar hanya bisa memberikan nilai kekerasan dengan kondisi anil (lihat tabel uji kekerasan gambar 4.3), dengan demikian nilai kekerasan hasil pengujian masih menunjukkan kondisi normal.Mengingat turbin mengalami putaran yang sangat tinggi sehingga terjadi regangan yang dipengaruhi oleh kekerasan, sebelum putus mengalami pengecilan diameter atau necking. 


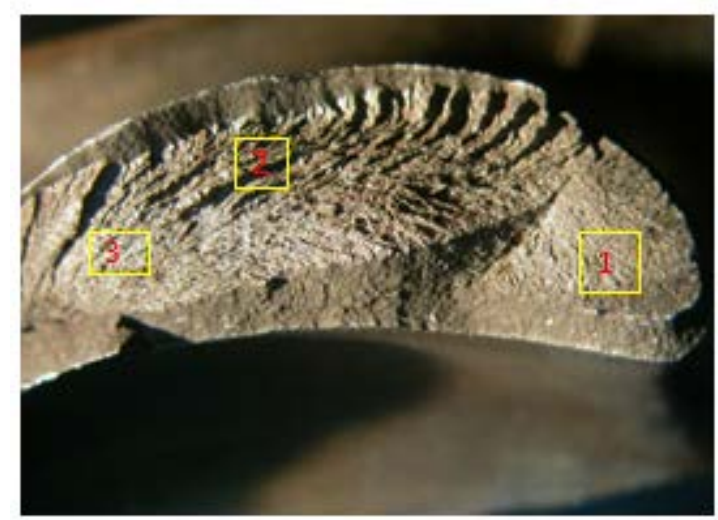

Gambar 4.Foto pengujian SEM pada sudu turbin uap untuk mengamati karbida logam pada material martensitic stainless steel 410
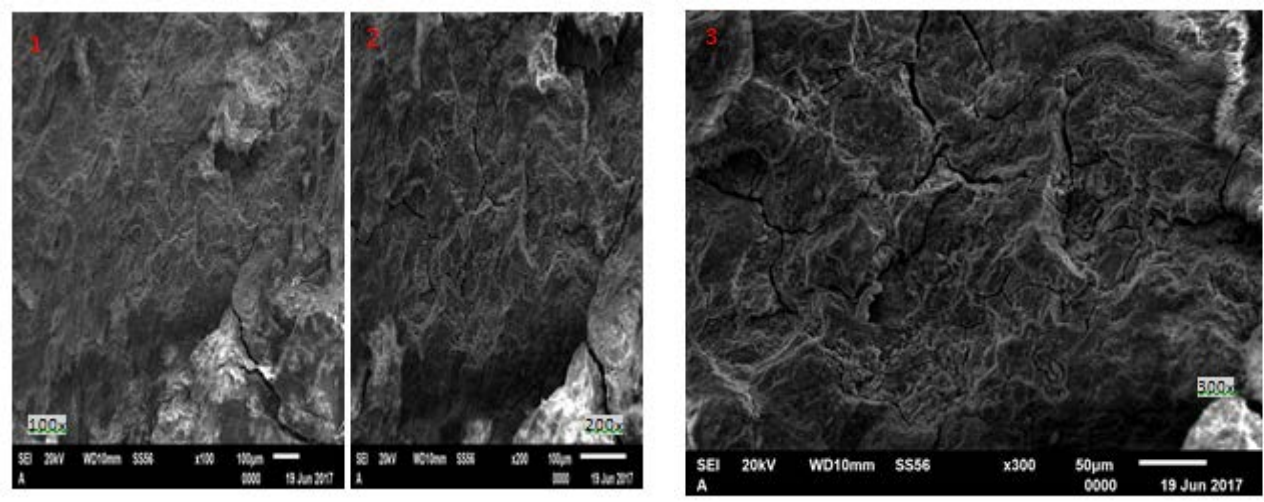

Gambar 5. Hasil foto uji SEM pada sudu turbin uap dengan pembesaran 100 X, pembesaran 200 X dan pembesaran $300 \mathrm{X}$.
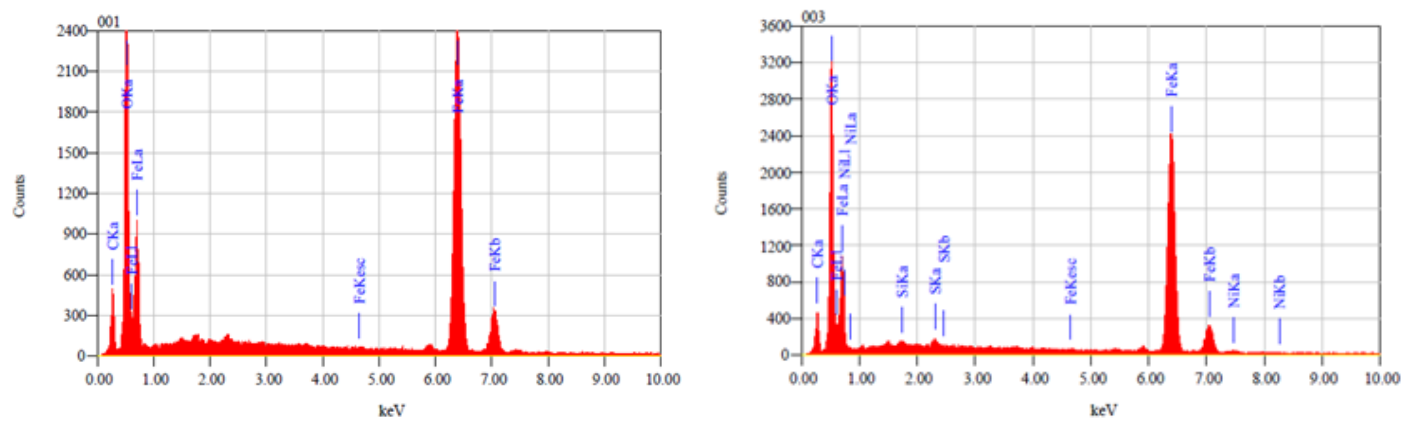

Gambar 6.Spektrum EDS unsur - unsur didalam karbida, mengamati karbida logam pada benda uji martensitic stainless steel 410 . 
Muhamad Cahyadi, Analisa Kerusakan Sudu Turbin Uap Material Martensitic Stainless Steel 410 Pada Stage

Terakhir
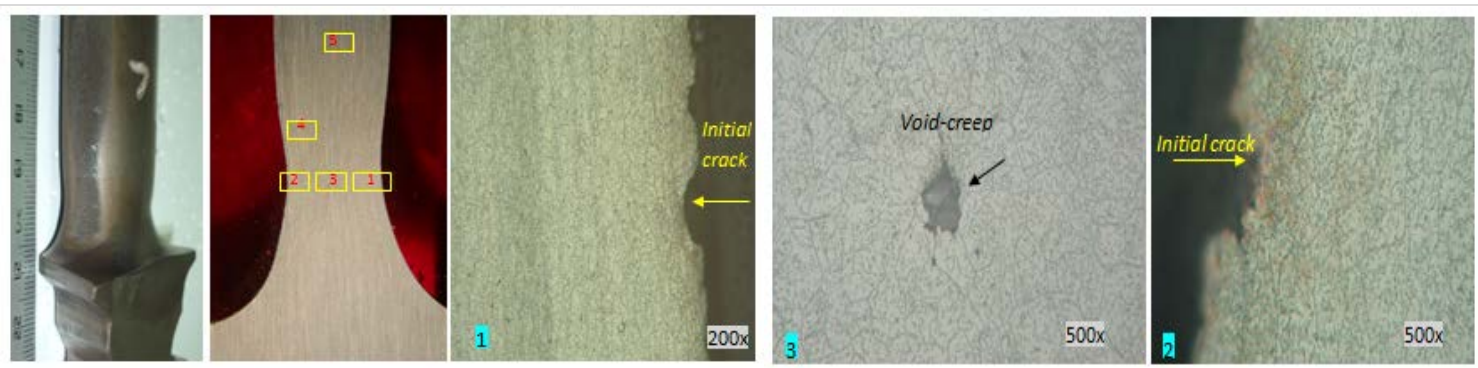

Gambar 7.Foto struktur mikro martensitic stainless steel 410 yang dilakukan dengan Etsa Kalling’s pada austenisasi.

Gambar 4 dan 5 menunjukan foto mikroskop optik SEM material martensitic stainless steel 410 setelah di austenisasi . Dari hasil pengujian SEM menggambarkan bahwa pada permukaan patahan Turbin Blade / sudu turbin telah mengalami perlakuan panas selama operasional. Analisa SEM dan komposisi kimia atau EDS menunjukkan telah terjadinya proses deformasi akibat tumbukan dengan groove atau alur dudukan sudu yang disebabkan oleh kompresi pada permukaan sudu turbin. Pola kerusakan akibat kompresi menyebabkan keregangan yang semakin besar antara kaki sudu (Christmass tree) dan permukaan groove.

\section{KESIMPULAN}

1. Berdasarkan analisa laborat atau pengujian, turbin uap pada saat di operasikan putarannya terus naik dan tidak terkendali (over speed) sehingga menyebabkan overload, terjadi patah akibat beban impak/berlebih danmenghantam sudu - sudu turbin yang lain.

2. Berdasarkan pengamatan visual terhadap kerusakan ditemukanjejakpatah statik akibat beban impak/berlebihdengan sudut patahan 45o.Kaki sudu (Chrismast tree) tampak jejak deformasi akibat benturan.

3. Berdasarkan hasil uji struktur mikro dari material sudu turbin dalam kondisi normal. Peristiwa patah pada daerah necking terjadinya akibat benturan dari patahan sudu turbin pada putaran tinggi.

4. Analisis kerusakan pada sudu - sudu turbin telah dilakukan dengan melihat dan membandingkan kondisi fisik kerusakan, kondisi operasi dan termasuk struktur mikro bahan. Hasil analisa kerusakan pada sudu yang terjadi di akibatkan oleh putaran turbin uap yang terus naik dan tidak terkendali (over speed) pada saat di operasikan.

\section{DAFTAR PUSTAKA}

1. Viswanathan, R., Damage Mechanisms and Life Assessment of High -Temperature Components.

2. ASM volume 11, Failure analysis and prevention.

3. Daryanto, Ilmu Metalurgy. Satu nusa, Bandung, Oktober 2010

4. D,N. Adnyana, Struktur dan Sifat Mekanis Material Logam, Diktat Mata Kuliah Program Pasca Sarjana (S2) ISTN Jakarta, 2003.

5. Christopher J, Mc Cauley, Machinery's Handbook, 29th Edition, 2012

6. Edin supardi, Pengujian logam. Angkasa, Bandung. 1994 